\title{
Evaluation of selected heavy metals on the artisanal gold mining sites in North Rift Region, Kenya
}

\author{
Yego, $\mathrm{E}^{1^{*}}$ and Kebenei. $\mathrm{S}^{2}$ \\ ${ }^{1}$ Department of Environmental Studies, University of Eldoret, Kenya \\ ${ }^{2}$ Physical and Biological Department, Kabarak University, Kenya \\ * E-mail of the corresponding author: yegoeliud@yahoo.com
}

\begin{abstract}
ASGM activity significantly contributes to the economies of developing countries with a consequent impact on the socio-ecological systems. The impacts are largely due to the wide use of mercury in the extraction processes. It also deforestates the exploited areas with consequent loss of biodiversity and ecosystem functions. ASGM has varied impacts of adverse health effects and it is said that mercury has more significant health effects than other heavy metals $(\mathrm{Cd}, \mathrm{Pb}, \mathrm{As}$, and $\mathrm{Cr})$. Due to dearth in the studies on artisanal mining in Kenya, the study sought to evaluate the concentration levels of selected heavy metals on the artisanal mining sites in Nandi and West Pokot Counties of Kenya in order to determine their nature, concentration levels and suggest mitigation measure. The study was done in two artisanal gold mining sites in Kapsaos in Nandi County and Sekker in West Pokot County in Kenya and employed a comparative analysis to examine the attributes of these locational spaces. Thirteen samples were randomly collected from tailings at different points from the tailing disposal site in Kapsaos areas and Sekker site. The samples were transported prepared and stored at Environmental Chemistry Laboratory, the University of Eldoret where it was subjected to Atomic Absorption Spectroscopy (AAS). The laboratory analysis results showed that the samples from both artisanal gold mining sites contained several heavy metals which included Chromium, Cadmium, and Lead. Overall, the mining sites in Nandi County had the following concentration of $\mathrm{Cr}, 0.4195 \mathrm{ppm}, \mathrm{Cd}, 0.2470 \mathrm{ppm}$, and $\mathrm{Pb}, 0.6300 \mathrm{ppm}$, while the mining sites in West Pokot county had the following concentrations: $\mathrm{Cr}, 0.1790 \mathrm{ppm}$; $\mathrm{Cd}, 0.0050 \mathrm{ppm}$; and $\mathrm{Pb}, 0.7400 \mathrm{ppm}$. Besides, the concentrations levels of Lead and Cadmium were above the WHO guidelines. A casual look at the concentration levels indicates that the mining sites in Nandi County have higher concentration levels of selected heavy metals $(\mathrm{Pb}, \mathrm{Cd}$ and $\mathrm{Cr})$ that in West Pokot County which was attributable to the ASGM activities. The study concluded that ASGM activities excavates, destabilizes the stables states of elements and then concentrates them. Finally, the study recommends that ASGM be upscaled instead of being frowned upon. Further studies on the potential socioeconomic impacts on the ASGM activities in Western Kenya because the activity is considered a complementary/supplementary economic activity.
\end{abstract}

Keywords: Artisanal and small scale gold mining (ASGM), artisanal mining, selected heavy metals, mercury, heavy metal pollution

DOI: $10.7176 / \mathrm{JEES} / 10-6-12$

Publication date:June $30^{\text {th }} 2020$

\section{Introduction}

As early as 2004, several studies reported ASGM activities generated between $10 \%$ to $15 \%$ of global gold output (Razanamahandry et al., 2018; Veiga, Angeloci-Santos \&Meech, 2014), however, estimates by Basu et al., (2015) ranged between 20\%-30\%. This indicates the increasing significance of the ASGM activities to multitudes who participate in the activity. The activities are primarily found in three regions of Asia, Africa and South America (Esdaile \& Chalker, 2018) where is positively seen by millions of persons as both a subsistence and a livelihood. But on the contrary, it is also the leading source of mercury pollution globally (Sippl, 2015). It is seen an economic mainstay activity providing direct employment to over two million people in rural sub-Saharan Africa (Hilson, 2009) with up to $80 \%$ of small-scale miners worldwide operating without formal authorization (Tschakert \& Singha, 2007).

In many developing countries, ASGM activity significantly contributes to the economies of those countries. Shandro, Veiga \& Chouinard (2009) observed that ASGM is responsible for over $90 \%$ of gold production in Mozambique and is a significant economic activity in Burkina Faso (Black et al., 2017). It makes up approximately $90 \%$ of the total mineral production in Democratic Republic of Congo (Bashwira et al., 2014) while accounting for a good percentage in the economy in Senegal (Persaud et al., 2017). In Tanzania, the sector contributes about $2.3 \%$ of the GDP (Kitula, 2006). In ASGM activities, gold is extracted mainly from alluvial deposits along rivers, 
waterways and terrestrial soils (Donkor et al., 2006) and varies widely in terms of its scope and practice (Schmidt, 2012).

ASGM is low tech, labour-intensive mineral processing and excavation activity(Hilson, 2009) and commonly uses mercury in its extraction process because of its availability, efficiency and historical usage, thus it can be inferred that with the global expansion of ASGM activities, there is a likely commensurate increase in the mercury usage(Basu et al., 2015). The artisanal mining processes mainly involves the excavation process where the natural vegetation is removed with the extensive excavation. Then, trial and error process of observation to identify the gold vein is used and once, observed, the rock bearing deposited is excavated either manually or mechanically for further processing (Esdaile \& Chalker, 2018; Donkor et al., 2006). Large boulders are mechanically pulverized and then soaked water to form a concentrated where the heavier gold-containing ores are caught and concentrated while the remaining concentrate is re-assembled in pans (Tschakert \& Singha, 2007).

The undesirable sediments are separated with final concentrate being mixed with mercury which is mixed with hand until a lump of mercury-gold amalgam is formed (Tschakert \& Singha, 2007). The amalgamation process may be repeated 3 or 4 times to maximize gold extraction (Esdaile \& Chalker, 2018). Excess mercury is then recovered and stored for re-use while the amalgam is then roasted in the in an open fire or a blowtorch to form a gold nugget (Esdaile \& Chalker, 2018). The amalgam is typically between $40 \%$ and $80 \%$ mercury and heatedoften with a torch or over a stove to evaporate the mercury and isolate the gold which while typically contain up to $5 \%$ residual mercury (Esdaile \& Chalker, 2018). This is the end-product that is readily sold (Tschakert \& Singha, 2007).

The ASGM activities pose a serious environmental threat to the human and the environmental activities due to its indiscriminate use of mercury (Donkor et al., 2006; Tschakert \& Singha, 2007). The resulting environmental pollution remains a threat to the socio-ecological balance (Donkor et al., 2006) and may trigger significant environmental and social problems because of the large deposits of wastes and/or tailings, which when exposed to air are oxidation and weathered by precipitation, and subsequently pollute water resources(Schwarzenbach et al., 2010). Cordy et al., (2011) estimated that only 50\% of the mercury used in recovered while 50\% is lost in two stages; the amalgamation and burning processes (Tschakert \& Singha, 2007) where 46\% is lost in tailings while $4 \%$ is lost in the burning process. Due to these estimates, ASGM activities are considered as the largest source of mercury pollution (Esdaile \& Chalker, 2018; Clifford, 2017). The usage of Mercury in Nandi County is illustrated by the image in Figure 1 below.

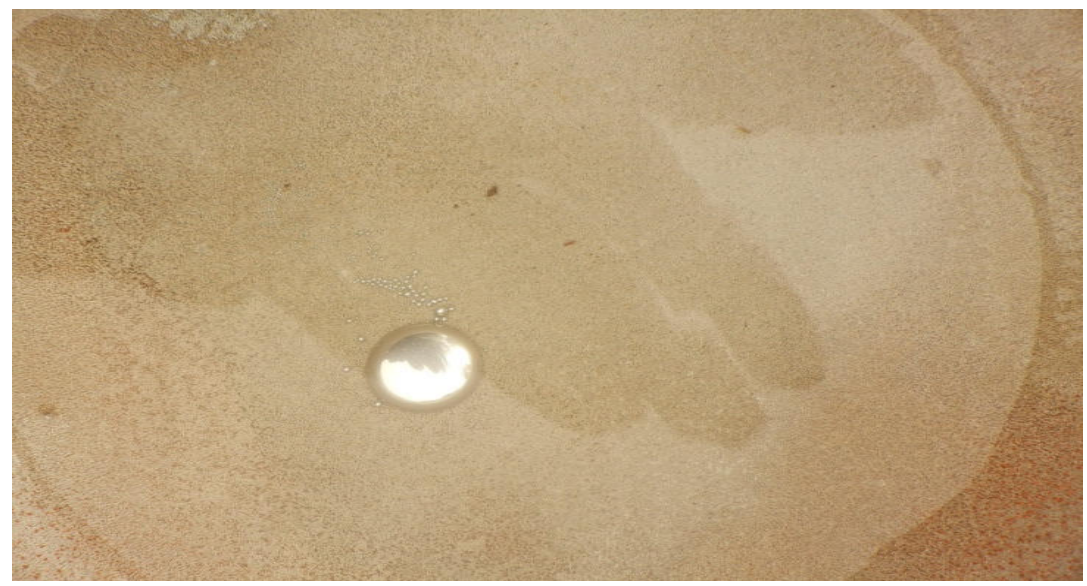

Figure1 Mercury use in mining in Nandi County

\subsection{Heavy metal pollution}

Artisanal small-scale gold mining, both at present and in the past, has had a major impact on soils and ecosystems (Grimaldi, Guédron \& Grimaldi, 2015; Shandro, Veiga \& Chouinard, 2009). The impact is largely due to the wide use of mercury in amalgamation a process (Veiga, Angeloci-Santos \& Meech, 2014; Miserendino et al., 2013) where the unrecovered mercury is either released directly into the environment or processed further depending on the level of sophistication (Esdaile \& Chalker, 2018). The real annual estimates of the amount of mercury being released into the environment by the ASGM activities ranges between 650 metric tonnes to 1600 metric tonnes (Esdaile \& Chalker, 2018; Telmer \& Veiga, 2009). 
This release is broken down into gaseous discharge or vaporized mercury into the atmosphere where approximately 350 to 450 metric tonnes are released(Telmer \& Veiga, 2009) and between 650 to 1000 metric tonnes of elemental and particulate mercury being released into the hydrosphere/environment(rivers, lakes, soils, tailings)(Veiga, Angeloci-Santos \& Meech, 2014; Schmidt, 2012; Basu et al., 2015). The magnitude of mercury use in ASGM activities is compounded by the fact that gold is precious and is fetching higher prices in the international markets and this tends to have a positive effect in the supply and usage of mercury (Esdaile \& Chalker, 2018).

In addition to Mercury pollution, ASGM activities also contribute to the increase in the concentration of heavy metals, metalloids such as arsenic (As) and heavy metals such as lead $(\mathrm{Pb})$, mercury $(\mathrm{Hg})$ and cadmium $(\mathrm{Cd})$ are naturally occurring pollutants but their environmental levels have increased in artisanal mining communities(Schwarzenbach et al., 2010). Several studies have cited the presence of metalloids and metals in various ASGM communities in several regions of the world including Ghana(Basu et al., 2015; Obiri et al.,(2016)), Zimbabwe (Mudyazhezha \& Kanhukamwe, 2014), Nigeria(Nuhu, Sallau \& Majiya, 2014), Ecuador (Miserendino et al., 2013) among others.

According to Grimaldi et al., (2015), ASGM is drastically changing land use with a considerable impact on the entire social-ecological system in several ways. First, the removal of top vegetation through the strip of the surface cover leading to the destruction of soil structure and affects the quality of water, second, the physical process of excavation and crushing damages the topography, third, the use of toxic metals and compounds in the amalgamation process without due care chemically pollutes air, surface and underground water and lastly, the indiscriminate disposal of tailings and waste affects the physical and chemical properties of natural resources.

ASGM also causes complete deforestation of the areas exploited and consequently a loss of biodiversity and ecosystem functions, landscape modifications and soil degradation (Grimaldi et al., 2015). Soil and water reservoirs (ground and surface water) are contaminated by the accumulation of heavy metals and metalloids through the discharge of mine tailings (Wauna \& Okieimen, 2011). For instance, in Southern Africa and Latin America, ASGM has led to contamination of water reservoirs affecting the health of the miners and community (Rojas, Drake et al, 2001). Evidence indicates that ASGM communities in Ghana are exposed to multiple toxic elements including $\mathrm{As}, \mathrm{Pb}, \mathrm{Cd}$, and $\mathrm{Cr}($ Basu et al., 2015).

\subsection{Health Effects}

Current studies into ASGM communities indicate that miners occasionally experience neurological effects, kidney effects, and possibly immunotoxic/ autoimmune effects from $\mathrm{Hg}$ exposure (Gibb \& O’Leary, 2014) and other heavy metals. Several metals and metalloids such as $\mathrm{Cd}, \mathrm{As}, \mathrm{Pb}$ and $\mathrm{Hg}$ are toxic to humans and have multiple adverse health effects, even at low concentrations (Schwarzenbach et al., 2010; Obiri et al., 2016). The health assessment reported kidney dysfunction, neurological disorders and symptoms, and immunotoxicity/autoimmune dysfunction in individuals living in or near an ASGM activity (Gibb \& O'Leary, 2014).

There are varied impacts of adverse health effects from the ASGM activities with Mercury having more significant health effects than other heavy metals such as cadmium, lead, aluminium, iron, and arsenic (Houston, 2011). Mercury is known to induce mitochondrial dysfunction (Houston, 2011) and has been associated with adverse cardiovascular outcomes such as coronary heart disease, myocardial infarctions, cerebrovascular accidents, cardiac arrhythmias, heart rate variability, atherosclerosis, and renal dysfunction (Basu et al., 2015). Other clinical consequences of mercury toxicity include, hypertension, increased carotid intima-media thickness and carotid artery obstruction, generalized atherosclerosis, and renal dysfunction, insufficiency, and proteinuria (Houston, 2011).

Evidence indicates that even at low exposure levels, Mercury may have adverse effects on the neurologic and body system which tend to vary according to individual susceptibility and other confounding variables (Karagas et al., 2012). The overall vascular effects of mercury include increased oxidative stress and inflammation, reduced oxidative defence, thrombosis, vascular smooth muscle dysfunction, endothelial dysfunction, dyslipidemia, and immune and mitochondrial dysfunction (Houston, 2011) with a variety of potential health effects ranging from foetal growth, a variety of health outcomes such as neurologic function, the cardiovascular system, and immune function in both adults and children (Gibb \& O'Leary, 2014). In South America countries of Peru and Brazil, exposure to mercury has resulted in kidney dysfunction that leads to kidney failure (Rodriguez et al., 2017). 
The main problem of heavy metals pollution is their persistence in soil and their tendency to bioaccumulation, their uptake by a human through food chain causing health problems and the poisoning of soil microorganisms (Odousoro et al., 2010). Therefore, exposure to ASGM activities had increased population morbidity leading to loss of productivity (Miserendino et al, 2013). Increase in tailings and sediments from mining sites have led to heavy metals contamination of ground and surface water and soil (Muezzinoglu, 2003). There is a dearth in the empirical studies on the artisanal mining among communities in Kenya and therefore, the study sought to evaluate the concentration levels of selected heavy metals on the artisanal mining sites in Nandi and West Pokot Counties of Kenya in order to determine their nature, concentration levels and institute any mitigation measure that improves the environmental, social and health effects on the miners and community.

\section{Materials and Methods}

\subsection{Study Area}

The study was done in two artisanal gold mining sites in Nandi and West Pokot Counties in Kenya. Nandi county is in the western region of Kenya and occupies an area of $2,884.4 \mathrm{Km}^{2}$, and it is bordered by the equator on the southern part and extend to the north at the latitude of $0^{0} 34^{\prime} \mathrm{N}$. The western bordering extends to longitude $34^{0} 45^{\prime} \mathrm{E}$ and the eastern boundary reach longitude $35^{\circ} 25^{\prime} \mathrm{E}$. Artisanal gold mining in Nandi county takes place in Kapsaos and Chemase wards (RoK, 2001). West Pokot County is situated on the Western boundary with Uganda and borders Turkana County to the North and North East, Trans Nzoia County to the South, Elgeyo Marakwet County and Baringo County to the South East and east respectively. The County lies within Longitudes 34047 ' and 350 49'East and Latitude 10 and 20 Northoccupies of approximately 9,169.4 square kilometres. The county has limited gold deposits along river Muruny, Seker and parts of Alale but alluvial mining takes place along river Murruny passing through sekker and Weiwei wards (ROK, 2002).

\subsection{Study Design}

The study employed a comparative design which applied the use of the geographic information systems (GIS). A geospatial analysis carves out geography into mutually exclusive spaces and then examines the attributes of these locational spaces (Depoy and Gitlin, 2011). The choice of the study design was based on the notion that this type of analysis was more relevant to making a comparison of attributes to specific locations. The GIS located the following estimate coordinate points for Nandi County: $0^{\circ} 0$ ' $49.95^{\prime} \mathrm{N}, 35^{\circ} 3^{\prime} 48.95^{\prime}$ ' $\mathrm{E}$; $0^{\circ} 0^{\prime} 49.95^{\prime} \mathrm{N}, 35^{\circ} 5^{\prime}$

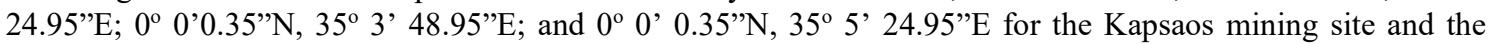
following estimate coordinate $1^{\circ} 31^{\prime} 57.10^{\prime \prime} \mathrm{N}, 35^{\circ} 24^{\prime} 42.84^{\prime \prime} \mathrm{E} ; 1^{\circ} 31^{\prime} 43.49^{\prime \prime} \mathrm{N}, 35^{\circ} 26^{\prime} 40.20^{\prime \prime} \mathrm{E}$; $1^{\circ} 31^{\prime} 27.10^{\prime \prime} \mathrm{N}$, $35^{\circ} 26^{\prime} 28.84^{\prime \prime} \mathrm{E}$; and $1^{\circ} 33^{\prime} 43.49^{\prime \prime} \mathrm{N}, 35^{\circ} 24^{\prime} 40.20^{\prime \prime} \mathrm{E}$ for the River Murruny, West Pokot County.

Once the locations had been identified the researcher purposively chose two wards in both counties; Kapsaos in Nandi County and sekker in West Pokot for the crucial comparative analysis of the attributes of artisanal mining activities. Once, completed the researcher embarked on the collection of samples from the mining sites in the two locations. The nature of mining in the two counties differs with underground mining being prevalent in Nandi County whereas alluvial mining being confined to West Pokot county. This illustrated by the images below, the left image shows an entrance to the mining shaft in Nandi County while the image on the right shows people undertaking panning in West Pokot County. 


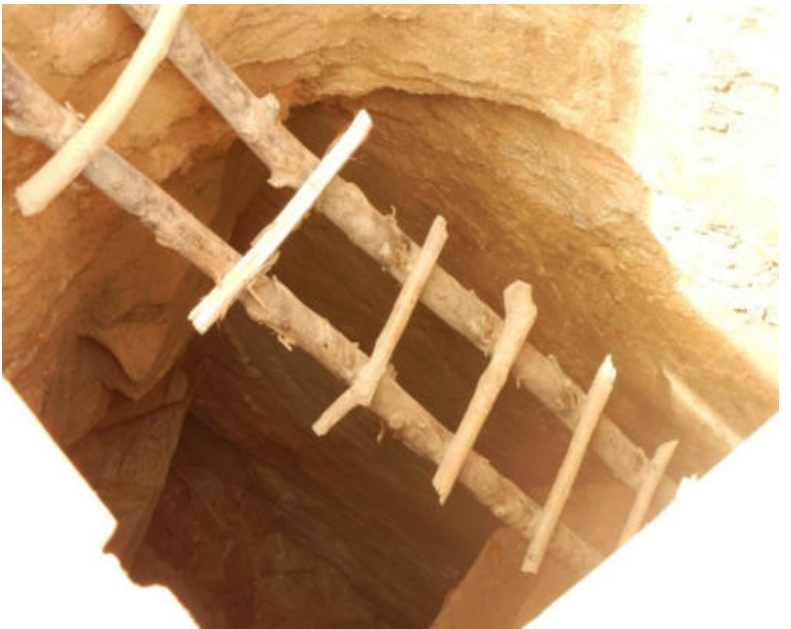

Figure 2 shaft in a mining site in Nandi County

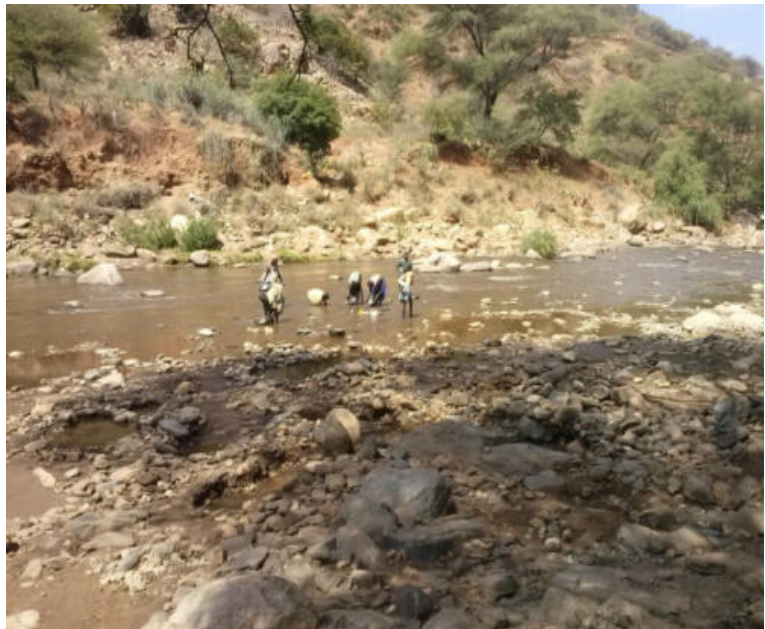

Figure 3 Alluvial mining in West Pokot County

\subsection{Sample Collection}

Thirteen samples were randomly collected from tailings at different points from the tailing disposal site in Kapsaos areas, Nandi County and Sekker site, West Pokot County. The collected samples were air-dried to a constant weight to avoid microbial degradation (Kakulu, 1993) and put in polyethene containers rinsed with dilute Nitric acid. The samples were deposited at the Environmental Chemistry Laboratory, University of Eldoret, Kenya for analysis using Atomic Absorption Spectroscopy (AAS).

\subsection{Laboratory Analysis}

From the collected samples, two (2) grams of each sample was weight and ground into a fine powder using an acid pre-washed mortar and pestle. Each powder of the sample was transferred into an acid-washed round bottom flask containing $20 \mathrm{~cm}^{3}$ concentrated acid. The mixture was evaporated on a hot plate; the solid residue was digested with concentrated with a 3:1 ratio mixture of concentrated $\mathrm{NHO}_{3}$ and $\mathrm{HClO}_{4}$ for a period of 30 minutes at room temperature. The digested mixture was heated to a steady temperature of $150^{\circ} \mathrm{C}$ for a period of 6 hours to allow $\mathrm{HClO}_{4}$ to evaporate completely (Jacob et al., 2009). The mixture was cooled to room temperature and filtered using number 541 Whatman filter paper into $50 \mathrm{~cm}^{3}$ volumetric flask and made into the standard mark using deionized water. The filtrate sample was stored in pre-cleaned polyethylene storage bottles ready for analysis. Heavy metals concentrations were determined using AAS (model: Varian spectra-200) at the Environmental Chemistry Laboratory, University of Eldoret, Kenya. The instruments settings and operating conditions were in accordance with the manufacturer's specifications. The instrument was calibrated with analytical grade standard metal solutions $(1 \mathrm{mg} / \mathrm{l})$ in triplicates.

\section{Results and Discussion}

After laboratory analysis, the results of the metal concentration are presented in Figure 1 below. The analysis of the samples precluded Mercury metal because of the challenges of determining the concentration of the $\mathrm{Hg}$ within the county at that point in time. This exclusion does not rule out a higher concentration of Mercury in the samples from the Nandi County mining as illustrated by the images showing the use of Mercury in the amalgamation process. 


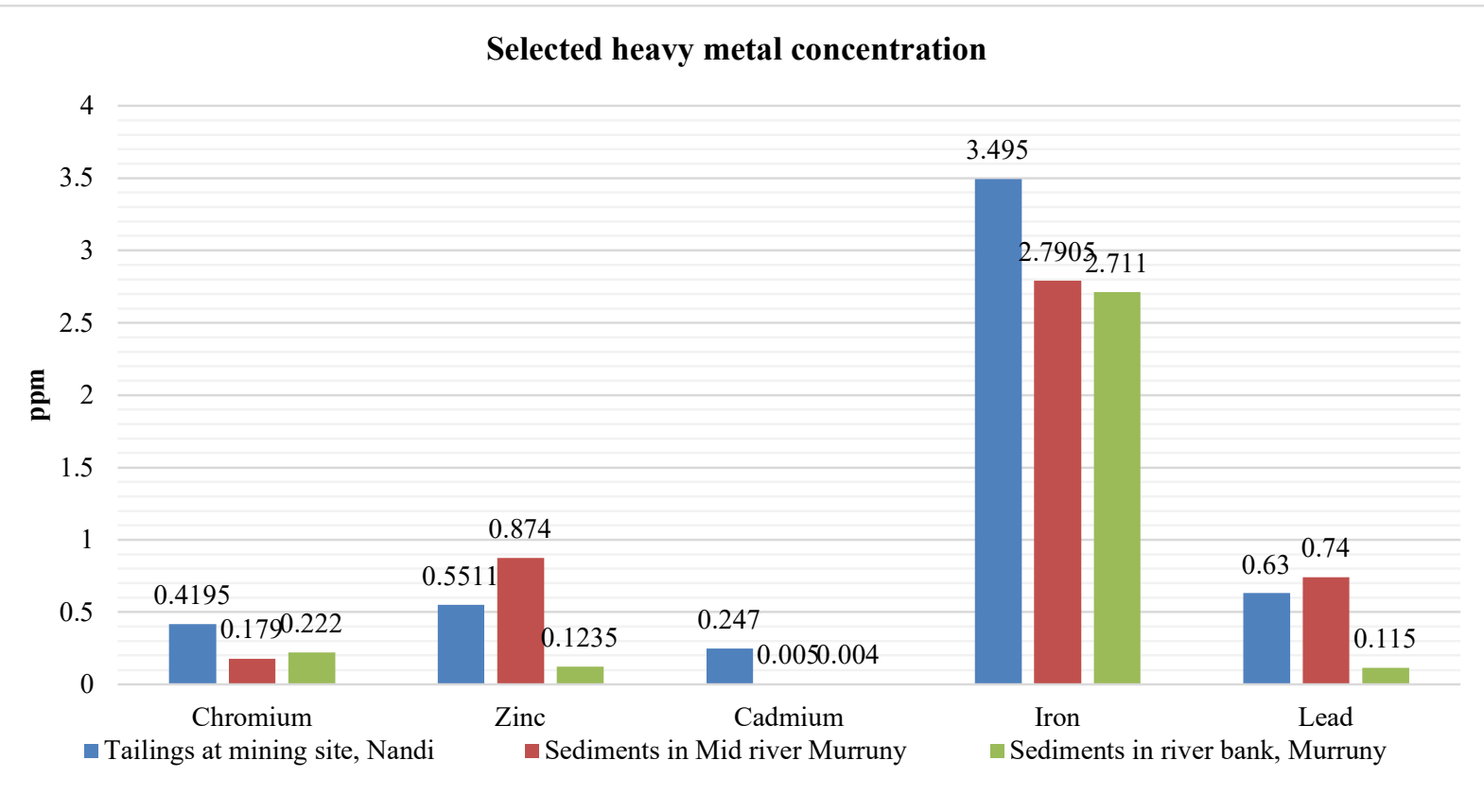

\section{Figure 1: Mean Concentration levels of selected heavy metals}

Based on the laboratory analysis results, the samples from mining sites in Nandi and West Pokot County contained several trace elements which included Chromium, Zinc, Cadmium, iron and Lead. Overall, the mining sites in Nandi County had the following concentration of Cr, 0.4195 ppm, Zn, 0.5511 ppm, Cd, 0.2470 ppm, Fe, 3.4950 ppm and $\mathrm{Pb}, 0.6300 \mathrm{ppm}$, while the mining sites in West Pokot county had the concentrations of the heavy metals: Cr, 0.1790 ppm; Zn 0.8470 ppm; Cd, 0.0050 ppm; Fe, 2.795 ppm; and $\mathrm{Pb}, 0.7400$ ppm on the river bed and concentration of $\mathrm{Cr}, 0.2220 \mathrm{ppm}$; $\mathrm{Zn} 0.1235 \mathrm{ppm}$; $\mathrm{Cd}, 0.0040 \mathrm{ppm}$; Fe, $2.711 \mathrm{ppm}$; and $\mathrm{Pb}, 0.1150 \mathrm{ppm}$ on the sediments.

In comparison, the average Iron concentration levels in Nandi mining area was 3.4195ppm while in West Pokot are was $2.7905 \mathrm{ppm}$ at the midriver and $2.711 \mathrm{ppm}$ on the river bank. The average Zinc concentration in Nandi mining area was $0.5511 \mathrm{ppm}$, while in West Pokot, the mid-river was $0.1874 \mathrm{ppm}$ and riverbank was $0.1235 \mathrm{ppm}$. The average Cadmium concentration in Nandi mining area was higher $0.247 \mathrm{ppm}$ while in West Pokot, the concentration at midriver was $0.005 \mathrm{ppm}$ and at the river bank was $0.004 \mathrm{ppm}$. The average Lead concentration in Nandi was $0.63 \mathrm{ppm}$ while in West Pokot the, mid-river had $0.74 \mathrm{ppm}$ and $0.115 \mathrm{ppm}$ on the river bank. Lastly, the average Chromium concentration in Nandi was 0.4195 while in West Pokot it was $0.179 \mathrm{ppm}$ at the river bank and $0.222 \mathrm{ppm}$ at mid-river.

Both Iron and Zinc are are essential nutrients required for various biochemical and physiological function(Tchounwou et al., 2012) and the concentration of Zinc(0.874ppm \& $0.551 \mathrm{ppm})$ in samples from both Nandi and West Pokot counties was lower than WHO/FAO recommended guideline value of 5.0 ppm for Zinc, while the concentration of Cadmium in Nandi mining site( $0.247 \mathrm{ppm})$ was higher against WHO/FAO recommended guideline value of $0.01 \mathrm{ppm}$. The concentration of Lead in Nandi mining site $(0.63 \mathrm{ppm})$ and West Pokot site $(0.74 \mathrm{ppm}$ were higher than the WHO/FAO recommended guideline value of $0.30 \mathrm{ppm}$. lastly, the concentration levels of Chromium in Nandi mining sites $(0.4195 \mathrm{ppm})$ and West Pokot sites $(0.222 \mathrm{ppm})$ were way below the against WHO/FAO recommended guideline value of $0.05 \mathrm{ppm}$. The WHO/FAO recommended guideline value for Mercury is of $0.030 \mathrm{ppm}$

The concentration of the selected heavy metal (Lead and Cadmium) where higher than the WHO/FAO recommended levels however, their impacts on the miners could not be ascertained. Further, the use of Mercury in the amalgamation process could compound the health of the miners but the measurement of long - term impacts of these metals would require a longitudinal study. Several studies have profiled high concertation levels of As and $\mathrm{Hg}$ with other heavy metals elements $\mathrm{Cd}, \mathrm{Cr}, \mathrm{Pb}$ and $\mathrm{Zn}$ having varying concentrations (Van Straaten, 2000). 
A casual look at the concentration shows that the mining sites in Nandi County have higher concentration levels of selected heavy metals $(\mathrm{Pb}, \mathrm{Cd}$ and $\mathrm{Cr}$ ) that in West Pokot County. This finding would be associated with anthropogenic activities of underground artisanal gold mining as opposed naturally occurring rock weathering processes. First, all the concentration levels of the metals sampled including essential metals (Iron and Zinc) are higher when compared yet both counties have more or less similar altitudes and agro-ecological zone. Due to this, the rate of rock disintegration would be similar and thus there would be no difference in the concentration levels.

Second, the type of mining being undertaken in the sites would explain the levels of concentrations. Shaft mining is predominant in Nandi County significantly disturb the concentration levels of heavy metals which are occurring in the natural states as opposed to alluvial mining which occurs in West Pokot county. The anthropogenic ASGM process of excavation, crushing and amalgamation process would disturb the elements and introduce them to the surface and concentrate them and in the process highlight the differences in concentration levels of these metals. This finding is supported by previous studies which indicated that occurrence of increased concentrations of heavy metals in the tailings is an indication of human-induced perturbations rather than natural enrichment through geological weathering (Davies, Tomlinson \& Stephenson 1991; Binning \& Baird, 2005; Eja et al., 2008).

Thirdly, empirical studies on ASGM activities have indicated that the bulk of the accumulated mercury occurs naturally in crystalline lattices but anthropogenic activities cause the secondary accumulation of Mercury (Grimaldi, Guédron\& Grimaldi, 2015). This occurs through the soil disturbance which tends to impede soil drainage and thereby favouring methylation of $\mathrm{Hg}$ (Grimaldi et al., 2015; Guedron et al., 2011b). Further, the studies on AGSM activities have reported the concentration levels of several known heavy metals which include $\mathrm{As}, \mathrm{Cd}, \mathrm{Cr}, \mathrm{Pb}$ alongside other metals such as aluminium, copper, manganese, nickel, selenium, and zinc metals. These studies include those done in ASGM sites in Ghana (Basu et al., 2015; Obiri et al., 2016), Ecuador (Miserendino et al., 2013). According to these studies, there is a link between ASGM activities and prevalence of these metals. There is no evidence to support their introduction of these selected metals into ASGM mining nor dispute the occurrence of the heavy metals in the mining processes. The only artificial ingredient introduced is the mercury which is used in the amalgamation process. Thus, processing of gold tends to release residual toxic materials into the environment while concentrating heavy metals (Razanamahandry et al., 2018).

\section{Conclusion}

The study has shown that ASGM activity despite being an informal activity is growing in leaps and bounds and significantly contributes to economies of developing countries in Africa, Asia and South America. The use of Mercury among the miners is synonymous with the mining activity itself because of the lack of options. On one hand, the prices of gold in the international markets rumps up the demand for gold and this, in turn, increases the prospectors who will use the easiest route to obtaining gold nuggets, that is the use of mercury. Thus, the process introduces and concentrates the heavy metals in the environments. Further, the study showed that most common metals in the ASGM sites are Mercury, Lead, Chromium, Cadmium and Arsenic which are derived anthropogenically into the environments by these activities. In time, their concentrations may breach the WHO/FAO concentration levels guidelines and pose a serious threat to the socio-ecological system. And because many ASGM communities in Sub-Saharan Africa are completely unaware of the dangers of the exposure of the heavy metals, they continue to mine without due care of the effects of the heavy metals.

\section{Recomendation}

ASGM has proved to be a significant livelihood and complementary activity to agriculture in sub-Saharan Africa and therefore this activity should be given due attention. ASGM is a resilient activity with a great propensity for grass-roots organization and management, and such capacity should be built upon and supported. The health and environmental standards should be encouraged and followed through. The policymakers should seek ways to improve practices in ASGM among them is the reduction or introduction of mercury-free technologies and general training and occupational health and safety measures Importantly, improvements in the ASGM practices geared towards safeguarding the socio-ecological systems can be cost-effective and beneficial to the environmental and economic performance of an ASGM community, thereby initiating change in the sector.

\section{Suggestion for Further Studies}

The study was limited to the identification of selected heavy metals in artisanal mining activities in the North Rift region, Kenya and this leaves avenues for other studies relating to ASGM activities in the region. Therefore, 
future studies may attempt to focus on the socio-economic impacts of ASGM activities, the health risks posed by ASGM activities and other related issues.

\section{References}

Basu, N., Nam, D.H., Kwansaa-Ansah, E., Renne, E.P. and Nriagu, J.O., 2011. Multiple metals exposure in a small-scale artisanal gold mining community. Environmental Research, 111(3), pp.463-467.

Basu, N., Clarke, E., Green, A., Calys-Tagoe, B., Chan, L., Dzodzomenyo, M., Fobil, J., Long, R.N., Neitzel, R.L., Obiri, S. and Odei, E., 2015. Integrated assessment of artisanal and small-scale gold mining in GhanaPart 1: Human health review. International journal of environmental research and public health, 12(5), pp.51435176.

Black, P., Richard, M., Rossin, R. and Telmer, K., 2017. Assessing occupational mercury exposures and behaviours of artisanal and small-scale gold miners in Burkina Faso using passive mercury vapour badges. Environmental Research, 152, pp.462-469.

Clifford, M.J., 2017. Assessing releases of mercury from small-scale gold mining sites in Ghana. The Extractive Industries and Society, 4(3), pp.497-505.

Cordy, P., Veiga, M.M., Salih, I., Al-Saadi, S., Console, S., Garcia, O., Mesa, L.A., Velásquez-López, P.C. and Roeser, M., 2011. Mercury contamination from artisanal gold mining in Antioquia, Colombia: The world's highest per capita mercury pollution. Science of the Total Environment, 410, pp.154-160.

Davies, C.A., Tomlinson, K. and Stephenson, T., 1991. Heavy metals in River Tees estuary sediments. Environmental Technology, 12(11), pp.961-972.

DePoy, E. and Gitlin, L.N., 2011. Introduction to Research Understanding and Applying Multiple Strategies. 4th.

Donkor, A.K., Nartey, V.K., Bonzongo, J.C. and Adotey, D.K., 2006. Artisanal mining of gold with mercury in Ghana. West African Journal of Applied Ecology, 9(1).

Eja, M.E., Abriba, C., Etok, C.A., Ikpeme, E.M., Arikpo, G.E., Enyi-Idoh, K.H. and Ofor, U.A., 2008. Seasonal occurrence of Vibrios in water and shellfish obtained from the Great Kwa River Estuary, Calabar,

Nigeria. Bulletin of environmental contamination and toxicology, 81(3), pp.245-248.

Esdaile, L.J. and Chalker, J.M., 2018. The mercury problem in artisanal and small-scale gold mining. ChemistryA European Journal, 24(27), pp.6905-6916.

Gibb, H. and O'Leary, K.G., 2014. Mercury exposure and health impacts among individuals in the artisanal and small-scale gold mining community: a comprehensive review. Environmental health perspectives, 122(7), pp.667-672.

Grimaldi, M., Guédron, S. and Grimaldi, C., 2015. Impact of gold mining on mercury contamination and soil degradation in Amazonian ecosystems of French Guiana. Land-use change impacts on soil processes-tropical and Savannah ecosystems. Boston: Cab International, pp.95-106.

Guedron, S., Cossa, D., Grimaldi, M. and Charlet, L., 2011. Methylmercury in tailings ponds of Amazonian gold mines (French Guiana): Field observations and an experimental flocculation method for in situ remediation. Applied Geochemistry, 26(2), pp.222-229.

Guedron, S., Grimaldi, M., Grimaldi, C., Cossa, D., Tisserand, D. and Charlet, L., 2011. Amazonian former gold mined soils as a source of methylmercury: Evidence from a small-scale watershed in French Guiana. water research, 45(8), pp.2659-2669.

Hilson, G., 2009. Small-scale mining, poverty and economic development in sub-Saharan Africa: An overview. Resources Policy, 34(1-2), pp.1-5.

Houston, M.C., 2011. Role of mercury toxicity in hypertension, cardiovascular disease, and stroke. The Journal of Clinical Hypertension, 13(8), pp.621-627.

Jackson, R.N., Baird, D. and Els, S., 2005. The effect of the heavy metals lead ( $\mathrm{Pb} \mathrm{2+)}$ and zinc ( $\mathrm{Zn} \mathrm{2+)}$ on. Water $\mathrm{Sa}, 31(1)$, pp.107-116.

Karagas, M.R., Choi, A.L., Oken, E., Horvat, M., Schoeny, R., Kamai, E., Cowell, W., Grandjean, P. and Korrick, S., 2012. Evidence on the human health effects of low-level methylmercury exposure. Environmental health perspectives, 120(6), pp.799-806. 
Miserendino, R.A., Bergquist, B.A., Adler, S.E., Guimarães, J.R.D., Lees, P.S., Niquen, W., Velasquez-López, P.C. and Veiga, M.M., 2013. Challenges to measuring, monitoring, and addressing the cumulative impacts of artisanal and small-scale gold mining in Ecuador. Resources Policy, 38(4), pp.713-722.

Mudyazhezha, S., and Kanhukamwe, R. 2014. Environmental monitoring of the effects of conventional and artisanal gold mining on water quality in Ngwabalozi River, Southern Zimbabwe. International Journal of Engineering, 4(10), pp. 8269-8280

Nuhu, A.A., Sallau, M.S. and Majiya, M.A., 2014. Heavy metal pollution: the environmental impact of artisanal gold mining on Bagega village of Zamfara State, Nigeria. Research Journal of Pharmacological, Biological and Chemical Sciences, 5, pp.306-314.

Obiri, S., Mattah, P.A., Mattah, M.M., Armah, F.A., Osae, S., Adu-Kumi, S. and Yeboah, P.O., 2016. Assessing the environmental and socio-economic impacts of artisanal gold mining on the livelihoods of communities in the Tarkwa Nsuaem Municipality in Ghana. International journal of environmental research and public health, 13(2), p.160.

Obiri, S., Yeboah, P.O., Osae, S., Adu-kumi, S., Cobbina, S.J., Armah, F.A., Ason, B., Antwi, E. and Quansah, R., 2016. Human health risk assessment of artisanal miners exposed to toxic chemicals in water and sediments in the PresteaHuni Valley District of Ghana. International journal of environmental research and public health, 13(1), p.139.

Udousoro, I.I., Umoren, I.U. and Asuquo, E.O., 2010. Survey of some heavy metal concentrations in selected soils in South-Eastern parts of Nigeria. World Journal of applied science and Technology, 2(2), pp.139-14.

Razanamahandry, L.C., Andrianisa, H.A., Karoui, H., Podgorski, J. and Yacouba, H., 2018. Prediction model for cyanide soil pollution in artisanal gold mining area by using logistic regression. Catena, 162, pp.40-50.

Rodríguez, L.H.S., Rodríguez-Villamizar, L.A., Flórez-Vargas, O., Fiallo, Y.V., Ordoñez, Á. and Gutiérrez, M.D.C., 2017. No effect of mercury exposure on kidney function during ongoing artisanal gold mining activities in Colombia: A cross-sectional study. Toxicology and Industrial Health, 33(1), pp.67-78.

Schmidt, C.W., 2012. Quicksilver \& gold: mercury pollution from artisanal and small-scale gold mining.

Shandro, J.A., Veiga, M.M. and Chouinard, R., 2009. Reducing mercury pollution from artisanal gold mining in Munhena, Mozambique. Journal of Cleaner Production, 17(5), pp.525-532.

Sippl, K., 2015. Private and civil society governors of mercury pollution from artisanal and small-scale gold mining: A network analytic approach. The Extractive Industries and Society, 2(2), pp.198-208.

Schwarzenbach, R.P., Egli, T., Hofstetter, T.B., Von Gunten, U. and Wehrli, B., 2010. Global water pollution and human health. Annual review of environment and resources, 35, pp.109-136.

Tchounwou, P.B., Yedjou, C.G., Patlolla, A.K. and Sutton, D.J., 2012. Heavy metal toxicity and the environment. In Molecular, clinical and environmental toxicology (pp. 133-164). Springer, Basel.

Telmer, K.H. and Veiga, M.M., 2009. World emissions of mercury from artisanal and small-scale gold mining. In Mercury fate and transport in the global atmosphere (pp. 131-172). Springer, Boston, MA.

Tschakert, P. and Singha, K., 2007. Contaminated identities: Mercury and marginalization in Ghana's artisanal mining sector. Geoforum, 38(6), pp.1304-1321.

Veiga, M.M., Angeloci-Santos, G. and Meech, J.A., 2014. Review of barriers to reduce mercury use in artisanal gold mining. The Extractive Industries and Society, 1(2), pp.351-361. 